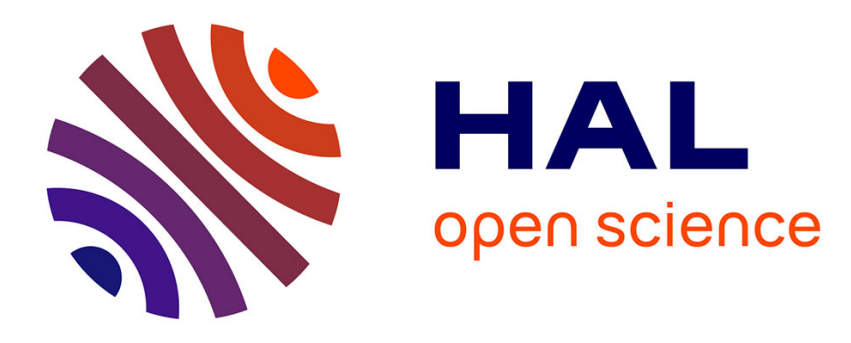

\title{
Material Characterization Tests and Modelling of Carbon Fibre T300/914 at Impact Rates of Strain
}

\author{
S. Hallett, C. Ruiz
}

\section{To cite this version:}

S. Hallett, C. Ruiz. Material Characterization Tests and Modelling of Carbon Fibre T300/914 at Impact Rates of Strain. Journal de Physique IV Proceedings, 1997, 07 (C3), pp.C3-465-C3-470. 10.1051/jp4:1997380 . jpa-00255537

\section{HAL Id: jpa-00255537 https://hal.science/jpa-00255537}

Submitted on 1 Jan 1997

HAL is a multi-disciplinary open access archive for the deposit and dissemination of scientific research documents, whether they are published or not. The documents may come from teaching and research institutions in France or abroad, or from public or private research centers.
L'archive ouverte pluridisciplinaire HAL, est destinée au dépôt et à la diffusion de documents scientifiques de niveau recherche, publiés ou non, émanant des établissements d'enseignement et de recherche français ou étrangers, des laboratoires publics ou privés. 


\title{
Material Characterization Tests and Modelling of Carbon Fibre T300/914 at Impact Rates of Strain
}

\author{
S.R. Hallett and C. Ruiz \\ Department of Engineering Sciences, University of Oxford, Parks Road, OXI 3PJ Oxford, U.K.
}

\begin{abstract}
This paper describes a series of tests which were conducted in order to obtain material and rate dependance data for carbon fibre T300/914. The results show there to be only a small amount of rate dependance. The information gained from the tests was then used as input data for the finite element code, DYNA-3D, in order to attempt to model the failure which occurred. Results have shown good predictions for initiation of damage but are not sufficient for delamination prediction of damage growth.
\end{abstract}

\begin{abstract}
Résumé: Cette publication décrit une série de tests qui ont été conduit afin d'obtenir des données sur la dépendance du taux de contrainte des fibres de carbone T300/914. Les résultats montrent qu'il n'existe qu'une faible dépendance. Les résultats obtenus à partir de ces tests ont ensuite été introduits dans un code à éléments finis, DYNA-3D, afin d'essayer de modéliser la fracture. Les résultats sont en bon accord concernant l'initiation de la fracture mais restent insuffisants pour prévoir la croissance des dommages par délaminage.
\end{abstract}

\section{INTRODUCTION}

In order to model impact damage of fibre reinforced composites using finite element methods, it is necessary to measure the mechanical properties of the material by testing small specimens under elementary loading conditions. For example, DYNA-3D [1] relies on the determination of the following values: tensile strength for fibre fracture, shear strength for delamination and matrix cracking, through-thickness tensile strength and crushing strength. The first three properties can be found from simple tests in tension and shear [2]. The last involves compression testing but is not regarded as of equal importance as the other three [3]. In general such tests are interpreted on the basis of a simple strength-of-materials approach, i.e. the stress is taken to be equal to the force divided by the appropriate cross section area. Whilst this approach is usually sufficient, in the case of laminated composites a more detailed knowledge of the stress distribution is required. In this paper, these types of test will be described together with their corresponding finite element analysis using DYNA3D. This permits not only the determination of elementary critical properties but also the study of the process of failure.

\section{TESTING METHODS}

\subsection{Material}

All the tests were done using carbon fibre T300/914 supplied by CIBA-GEIGY [4]. This is a unidirectionally reinforced pre-preg carbon/epoxy composite. The specimens were made up with alternating $0 / 90^{\circ}$ layers using the vacuum bag technique. The fibre volume fraction was 55 to $60 \%$. All specimens were $\mathrm{C}$-scanned before testing.

\subsection{Test Geometries}

The in-plane tension strength of the material was tested using the specimen shown in figure 1 [5]. Without the waisting in the centre it was found that failure occurred in the glue on the tabs. With waisting in the through-thickness direction failure occurred by shear between layers in the glueing tabs. The final design was chosen so as to achieve the maximum fillet radius, and hence the lowest stress concentration, while still achieving in-plane tensile failure in the gauge section. Figure 2 shows the finite element analysis which gives a stress concentration of 1.2 at the end of the lateral fillet where failure occurs in the actual tests (figure 3 ). 


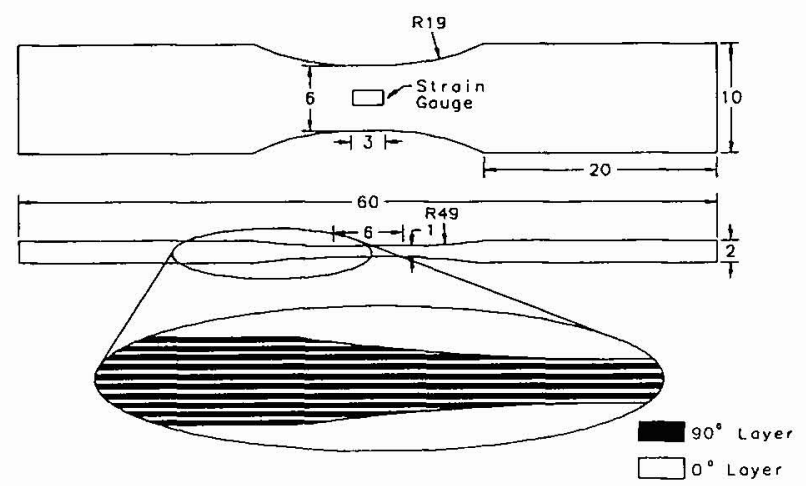

Figure 1: In-plane tension test specimen detail

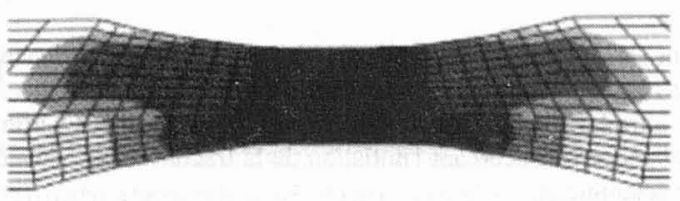

Figure 2: Stress analysis of in-plane tension specimen showing maximum longitudinal stress
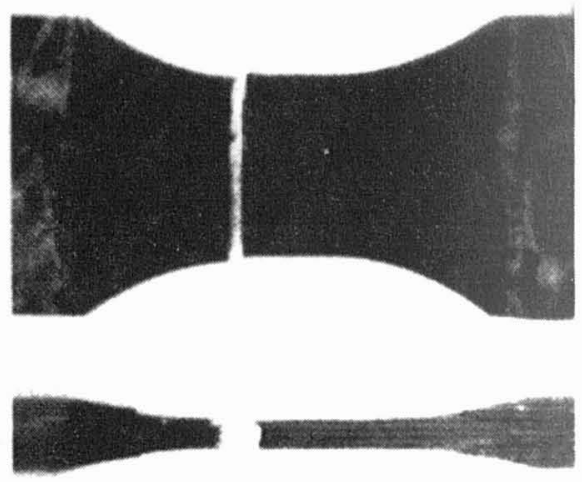

Figure 3: Photograph showing failed specimen (after removal from loading bars)

A specimen has been developed in order to examine through-thickness tensile strength (figure 4). The cross section area of the failure plane is governed by the strength of the glue holding the specimen to the loading bars. The fillet radius will cause a stress concentration and therefore the results can only be considered a lower limit of through-thickness strength. A greater radius could not be obtained as the length of the specimen is limited by the maximum number of layers which could be laid up. The analysis was completed with out the $2 \mathrm{~mm}$ parallel section in the centre which was added in order to allow direct measurement of strain with strain gauges glued onto the specimen. The stress in the central section was found to vary in the ratio $1: 1.18$ between the centre and the outside surface as shown by the finite element analysis results in figure 5 . The presence of the of the parallel gauge section does not significantly affect this value.

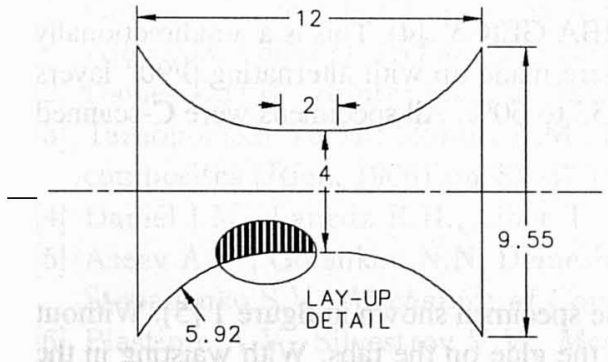

Figure 4: Through-thickness tension test specimen detail

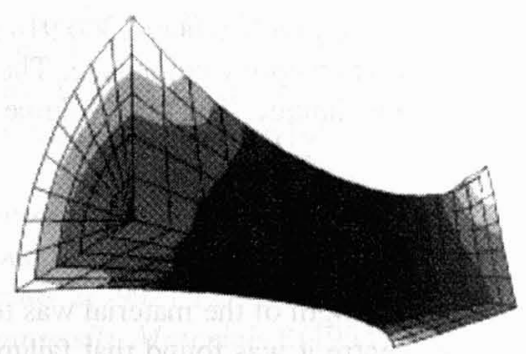

Figure 5: Stress analysis of throughthickness tension specimen showing maximum longitudinal stress 


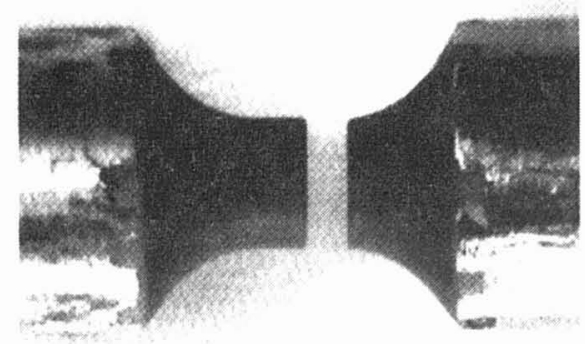

Figure 6: Photograph showing failed specimen

The shear strength of the material was measured using a single lap shear specimen as devised by Harding and Dong [5]. The geometry of the test piece as well as the lay up details are shown in figure 7. Figure 8 shows that failure consists of shear along an interlaminar plane. The specimen was designed so as to obtain as uniform as possible shear stress across the central plane within the constraints of the loading configuration [5]. The finite element analysis demonstrates the presence of a shear band between the two end notches. As shown in figures 9 and 10 , this band is fairly wide and although the stress peaks towards the notches it remains approximately constant over the failure plane. The stress concentration factor is 1.3 .

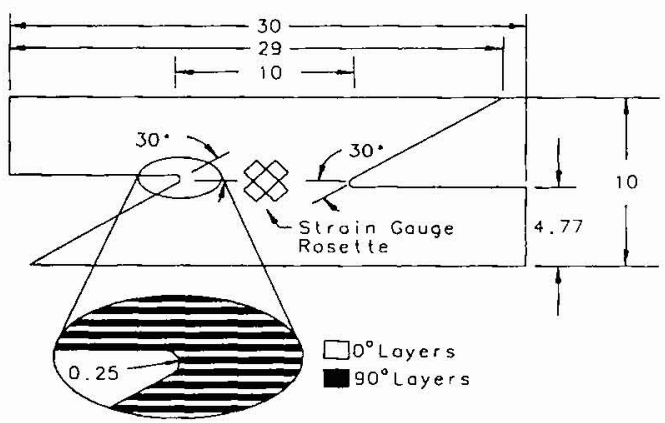

Figure 7: Shear test specimen detail

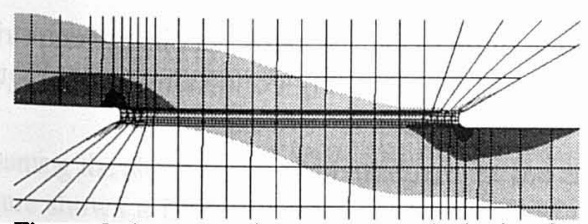

Figure 9: Shear specimen stress analysis showing maximum horizontal stress

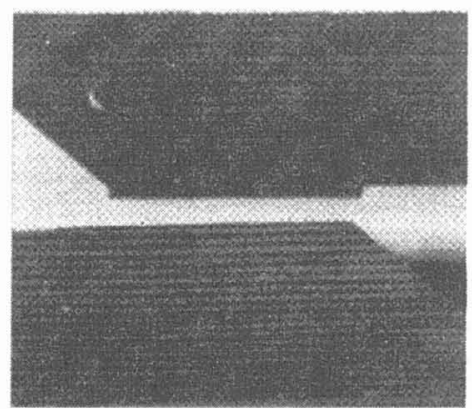

Figure 8: Photograph showing failed specimen (after removal from loading bars)

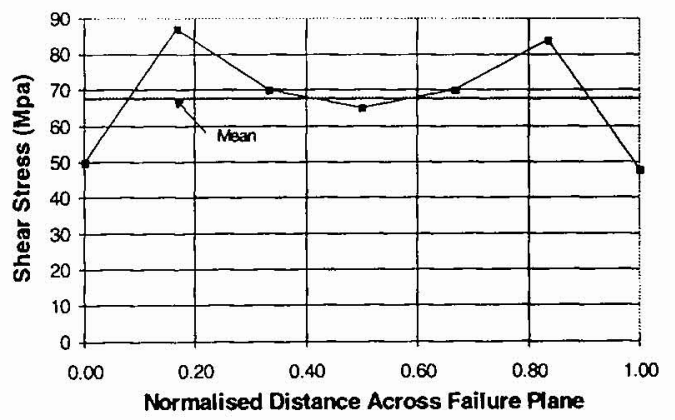

Figure 10: Stress distribution across shear failure plane 


\subsection{Apparatus}

A split Hopkinson bar apparatus was used in order to conduct the in-plane and through-thickness tensile tests. Specimens were glued to the loading bars using 3M-190 for the in-plane tests and 3M 9323 B/A for the through-thickness tests. Figure 11 shows the tensile apparatus.

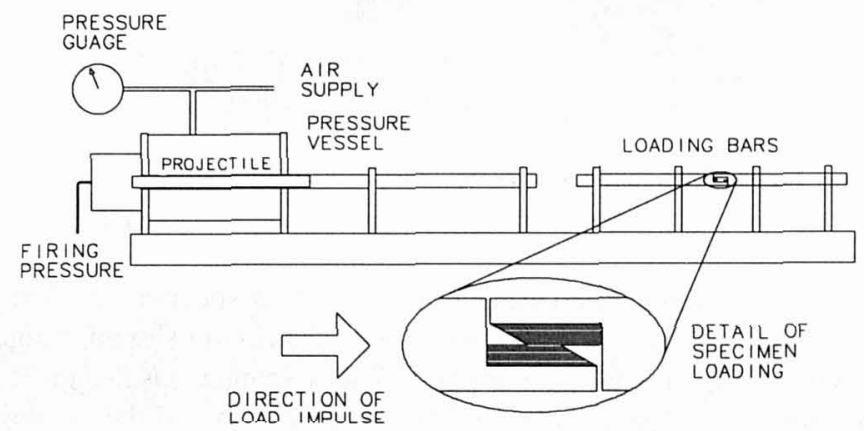

Figure 11: Compressive Hopkinson bar apparatus used for shear tests

A compressive Hopkinson bar apparatus shown in figure 12 was used for the shear tests.

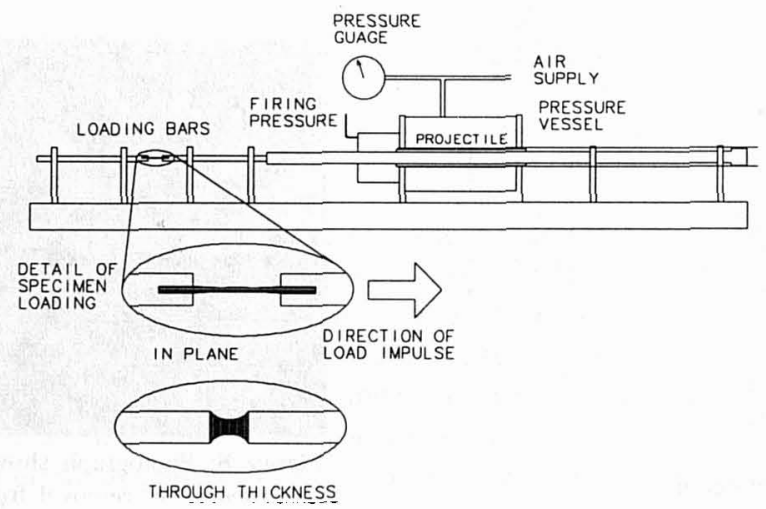

Figure 12: Tension Hopkinson bar apparatus used for throughthickness and in-plane tension tests

Quasi-static tests at a rate of approximately $1 \mathrm{~mm} / \mathrm{min}$ were done using the same specimen geometries as for the high strain rate tests on an Instron universal testing machine. Loading conditions were kept the same as for the high strain rate tests.

\section{RESULTS}

\subsection{In-Plane Tension Tests}

Testing results (figure 13) show a slight increase in stress and strain at increasing strain rate. The time history of each test has been used to obtain stress strain curves and hence an elastic modulus for the combined $\left[0 / 90^{\circ}\right]$ lay-up of $83.2 \mathrm{GPa}$. 


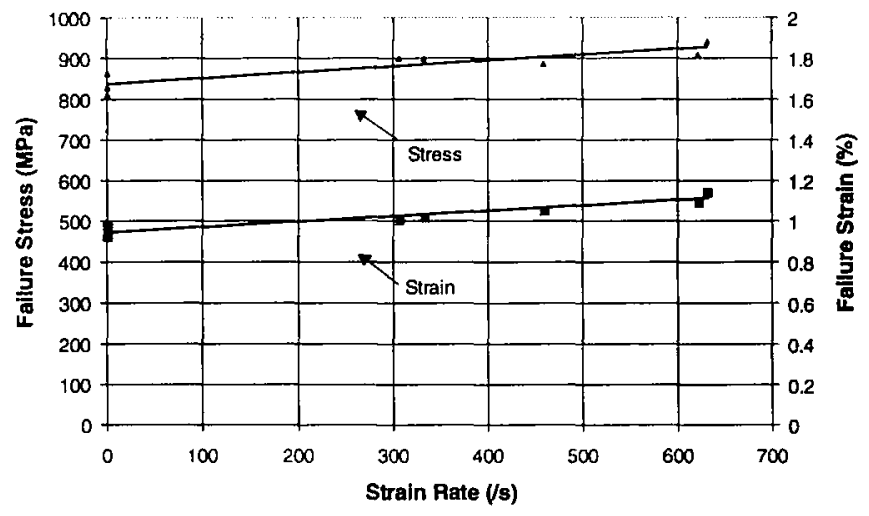

Figure 13:In-plane tension test results showing rate dependance

\subsection{Through-thickness tension tests}

Figure 14 shows the results of the through-thickness tests. The large amount of scatter in the data can be attributed to the fact that any amount of mis-alignment of the loading bars will produce substantial bending stresses when the loading force is applied.

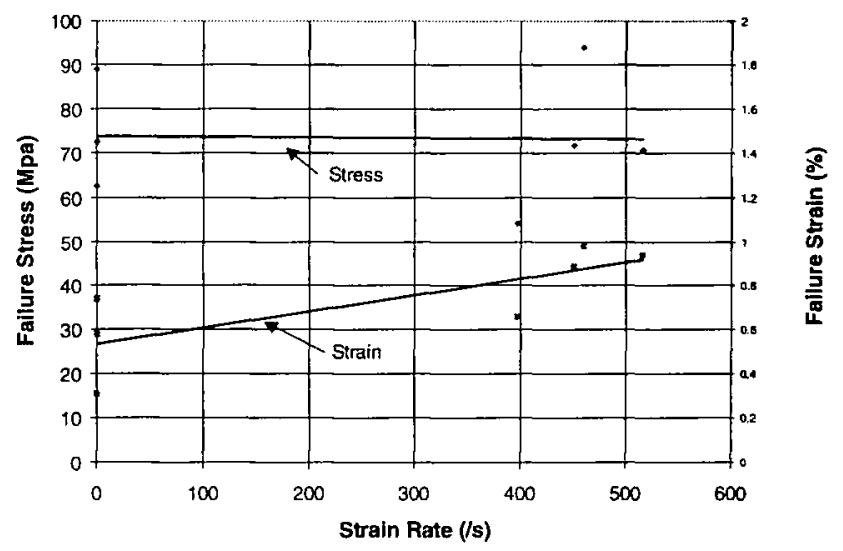

Figure 14: Through-thickness tension test results showing rate dependance

\subsection{Shear Tests}

Assuming the shear stress to be uniform across the failure plane, it can be calculated from the loading force. Figure shows a finite element analysis giving the stress distribution during loading. Strain was measured directly using strain gauges with a $1 \mathrm{~mm}$ gauge length glued at $45^{\circ}$ to the failure plane. High speed photography showed there to be no localised shear band, thereby validating this method. The results are shown in figure 15. 


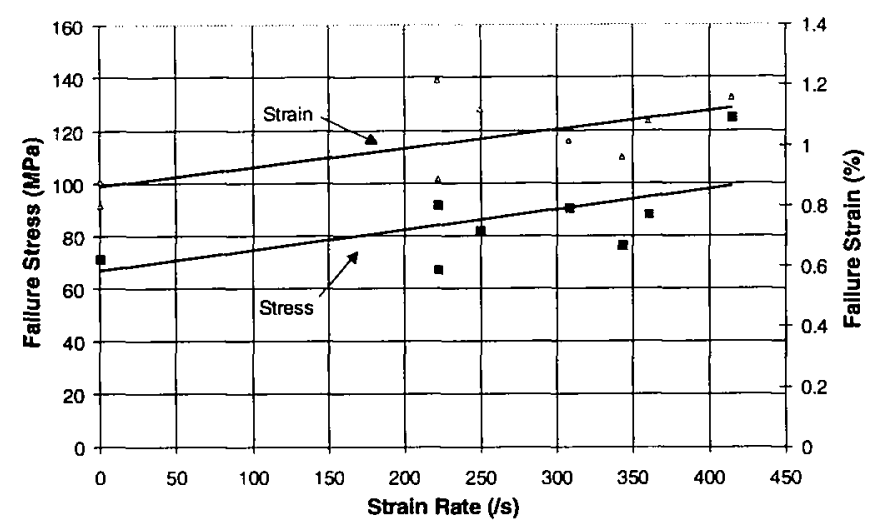

Figure 15: Shear test results showing rate dependance

\section{MODELLING}

Using the results gained from these tests a series of finite element models have been carried out using DYNA3D. Within DYNA-3D are a set of failure criteria based on maximum stress for fibre fracture, matrix cracking, matrix crushing and delamination. Each test has been modelled and the sequence of failure obtained [4]. The in-plane tension test shows failure to occur initially by fibre fracture. This is followed by matrix cracking in the same regions as well as delamination in the gluing tabs. The shear test model showed a good prediction of the failure plane but also showed fibre fracture which was not seen to occur. The through thickness test model is dominated by delamination with matrix cracking occurring in the same place. The results thus show DYNA to be capable of approximately predicting the initiation of failure. The progression of damage after initiation and failed shape predictions do not show good agreement with the test results in all cases.

\section{CONCLUSION}

In conclusion it can be seen that there is a small rate dependance in carbon fibre T300/914 but this is approximately of same order as the scatter of the experimental data. The tests described offer a good set of data for input into the finite element code. Providing both maximum strength and elastic modulii information.

The modelling has been shown the failure criteria in DYNA-3D to be adequate for predicting initial damage but incapable of satisfactorily modelling the growth of damage.

\section{REFERENCES}

[1] Hallquist J.O. and Stillman D.W., "VEC/DYNA-3D a non-linear dynamic analysis of structures in three dimensions - User Manual" 1991

[2] Harding J., Impact damage in composite materials (Lecture notes for the Stage de Formation Continue) 1996

[3] Ciba-Geigy, Fibredux 914 (Information sheet No. FTA 49f) 1989

[4] Hallett S. and Symons D., "Testing and modelling of impact failure mecanisms in carbon fibre". NAFEMS World Congress '97, Stuttgart 9-11 April 1997

[6] Dong L. and Harding J., Composites, vol. 25, no. 2, (1994) pp 129-138 